\title{
Occlusal traits in developmental dyslexia: a preliminary study
}

This article was published in the following Dove Press journal:

Neuropsychiatric Disease and Treatment

23 August 2013

Number of times this article has been viewed

\author{
Letizia Perillo' \\ Maria Esposito ${ }^{2}$ \\ Mariarosaria Contiello' \\ Alessandra Lucchese ${ }^{3}$ \\ Annamaria Chiara Santini ${ }^{2}$ \\ Marco Carotenuto ${ }^{2}$ \\ 'Department of Orthodontics, \\ Second University of Naples, Naples, \\ ${ }^{2}$ Clinic of Child and Adolescent \\ Neuropsychiatry, Department of \\ Mental Health, Physical and Preventive \\ Medicine, Second University of \\ Naples, Naples, ${ }^{3}$ Department of \\ Orthodontics, University of Ferrara, \\ Ferrara, Italy
}

Correspondence: Maria Esposito Clinic of Child and Adolescent Neuropsychiatry, Department of Mental Health, Physical and Preventive Medicine, Second University of Naples, Via Sergio Pansini, 5, 80I3। Napoli, Italy

Tel $+3908 \mid 5666988$

Fax $+3908 I 5666694$

Email maria.esposito2@unina2.it
Aim: The objective of the study reported here was to assess the orthodontic features in children affected by developmental dyslexia (DD).

Patients and methods: A total of 28 children affected by DD (22 boys, six girls; mean age: $9.78 \pm 1.69$ years) were compared with 51 healthy children ( 38 boys, 13 girls; mean age $9.41 \pm 1.48$; range $7-10$ years). Reading and writing skills were evaluated along with orthodontic features.

Results: The DD and control groups were not significantly different in terms of total intelligence quotient $(P=0.441)$ and writing skills $(P=0.805$ and $P=0.240$, respectively), whereas significant differences were observed between the DD group and control group in both word reading $(2.018 \pm 1.714$ vs $0.917 \pm 0.563 ; P=0.000)$ and non-word reading $(2.537 \pm 1.543 \mathrm{vs}$ $0.862 \pm 0.244 ; P=0.000$ ). Moreover, for many orthodontic features, there was no significant difference between the two groups; only in prevalence of diastemas $(57.14 \%, P=0.006)$, midline diastemas $(46.42 \%, P=0.007)$, overbite $>4 \mathrm{~mm}(71.42 \%, P=0.006)$ and overjet $>4 \mathrm{~mm}$ (53.57\%, $P=0.001)$, was there a statistically significant difference. According to univariate logistic regression analysis, the presence of diastemas (odds ratio [OR] 4.33; 95\% confidence interval [CI] 1.61-11.65), midline diastemas (OR 4.68; 95\% CI 1.61-13.43), an overbite $>4 \mathrm{~mm}$ (OR $1.75 ; 95 \%$ CI $0.64-4.71$ ), or an overjet $>4 \mathrm{~mm}$ (OR 2.76; 95\% CI 1.06-7.20) seems to play a role in the relationship between occlusal abnormalities and DD in children.

Conclusion: Children with DD tend to present with altered dental features, particularly in the area of the incisors, suggesting that a persistently different tongue kinematic profile may thus affect both the developmental variability of the tongue and lip and the occlusion.

Keywords: malocclusion, orthodontic features, learning disorder, kinematic profile

\section{Introduction}

The learning disabilities (LDs) are an heterogeneous group of academic performance disorders in children with a normal global development. LDs are diagnosed with standardized reading, writing, or maths tests scored below the age rank, schooling, and intelligence, in absence of medical or psychiatric conditions, sensory impairment, or lack of educational opportunities. ${ }^{1}$

About 5\% of schoolchildren present with a "specific learning disorder," defined as an unexpected failure to acquire adequate abilities in reading, writing, or mathematical skills not as a result of reduced intellectual ability, inadequate teaching, or social deprivation. Among these specific learning disorders, about $80 \%$ are reading disorders. ${ }^{2,3}$ In fact, developmental dyslexia (DD) could be considered the most frequent specific learning disorder, with a prevalence ranging from $5.0 \%$ to 
$17.5 \%$ in European children, independent of language and orthography. 4,5 "DD" has been defined as an unexpected, specific, and persistent failure to acquire efficient reading skills despite conventional instruction, adequate cognitive level, and sociocultural opportunity. ${ }^{6,7}$ Moreover, difficulty with reading and/or literacy acquisition represent/s only one/two of the various symptoms of this complex disorder, which involves the visual, auditory, and motor domains. ${ }^{8-11}$ Other symptoms include minor neurological signs, ${ }^{12}$ sleep complaints, ${ }^{13}$ motor impairment, ${ }^{14}$ social difficulties, ${ }^{15}$ and internalizing problems. ${ }^{1}$ Moreover, individuals affected by DD tend to have difficulty in accessing the phonological word forms after receiving normal access to the corresponding abstract lexical representation. ${ }^{16}$

However, the distinction between articulation or speech motor issues and difficulties relating to phonology and phonological awareness can be considered distinct even if related, and it is the latter specifically that have been most closely associated with DD. Conversely, in accordance with the cerebellum's role in language ${ }^{17}$ and its putative role in the organization of tongue movements, ${ }^{18}$ Hanly and Vanderberg $^{19}$ showed that during a picture-naming task, DD subjects demonstrated more tip-of-the-tongue responses and proportionally more errors in the phonological step, but not the semantic step, of word retrieval.

DD subjects tend to read printed words and non-word lists less accurately and slower than typically developing subjects, suggesting that the tongue movements and speech motor development are not uniform. ${ }^{20}$

Further, some studies have suggested a potential causative role of craniofacial morphology in childhood sleep disorders, ${ }^{21}$ which are usually linked to learning ${ }^{22-24}$ and behavioral impairment. ${ }^{25}$

In general, dental malocclusions and anatomo-functional anomalies of the mouth are known to be remarkably interrelated. ${ }^{26}$ In fact, the modeling forces of the muscles over the dental arches, when well balanced and harmonious, favor adequate occlusion, and any alteration in the functional mechanism may lead to alterations in bone development. Conversely, when muscles perform their function, they can model the bone's growth. ${ }^{26}$

Therefore, the existing relationship between the oral cavity and the orofacial muscular system requires that all orthodontists know how to identify not only malocclusions but also functional and muscular orofacial alterations so as to highlight and correct the muscular abnormalities that could impair oral functions such as tongue movements and speech motor development.
In fact, morphological alterations can cause functional alterations but not always phono-articulatory disorders, and when the compensatory mechanisms fail or require a greater degree of functional adaptation, the onset of speech and/or reading disorders may occur. ${ }^{27}$ Thus, a persistent different tongue kinematic profile during childhood may affect not only the development of tongue-jaw coordination but also of dental occlusion ${ }^{20}$ because of the effect of tongue and lip pressure on the position of the teeth, ${ }^{28}$ considering that tongue functions and kinematics work together with the upper and lower jaws' growth and dental occlusion morphology. ${ }^{20}$

In general, the cause and effect relationship between malocclusion and oral or psychological health is either nonexistent or considered weak ${ }^{29,30}$ and there are many areas that have not been investigated yet. As such, the putative correlation between learning disabilities and malocclusion has not yet been considered in clinical practice, as far as we are aware, even though a recent report pinpointed that a multi-component model of language abilities would best explain the relationship between specific language impairment and DD and the different profiles of impairment that could be observed. ${ }^{31}$

To the best of our knowledge, no studies about the correlation between the dental malocclusion and DD are present in clinical literature. Therefore, the aim of the present study was to assess the orthodontic features in a sample of children affected by DD.

\section{Patients and methods Study population}

The study population was enrolled from children referred for learning difficulties to the Child and Adolescent Neuropsychiatry Clinic at the Second University of Naples and was composed of 28 children (22 males and six females; mean age $9.78 \pm 1.69$ years) identified as being affected by DD according to specific neuropsychological assessment.

Exclusion criteria were any neurological (ie, epilepsy, primary headache, neuromuscular disorders) or psychiatric (attention deficit hyperactivity disorder, depression, behavioral problems) symptoms; mental retardation (intelligence quotient [IQ] $\leq 70$ ); borderline intellectual functioning (IQ 71-84); a hearing or vision problem; a language impairment and/or phono-articulatory problem; obesity, and/or the taking of an anticonvulsant or psychoactive drug.

The control group was composed of 51 typically developing children (38 males and 13 females; mean age 9.41 \pm 1.48 ) selected during a periodic control visit to the Orthodontics Department at the Second University of Naples, who were 
not significantly different in terms of age and sex from those in the study group and selected according to the same inclusion and exclusion criteria.

Each child underwent a neuropsychological assessment and an orthodontic evaluation by expert trained specialists.

Subjects in both groups were recruited from the same urban area; participants were all Caucasian and of middle socioeconomic status (between class 2 and class 3 [corresponding to $€ 28,000-€ 55,000 /$ year and $€ 55,000$ $€ 75,000 /$ year, respectively] according to the current Italian economic legislation parameters).

The study protocol was approved by the Departmental Ethics Committee of the Second University of Naples. The parents of all participating children gave their written informed consent. The study was conducted according to the criteria of the Declaration of Helsinki. ${ }^{32}$

\section{Neuropsychological assessment}

To determine the intellectual abilities of individuals in both study groups, their IQ was assessed using the Italian version of the Wechsler Intelligence Scale for Children Third Edition (WISC III), ${ }^{33,34}$ which is applicable for children ranging from 6 to 16 years old. The WISC III is composed of 13 distinct subtests divided into two scales, a verbal scale and a performance scale. The six verbal scale tests use language-based items, whereas the seven performance scale tests comprise visual-motor items that are less dependent on language. Five of the subtests in each scale produce scale-specific IQs: the verbal IQ and performance IQ, and the ten subtest scores produce a total intelligence quotient (TIQ). For this study, only the TIQ was considered.

Subsequently, for testing the reading and writing skills, word and non-word reading and writing tasks derived from the DDE-2: Batteria per la Valutazione della Dislessia e della Disortografia Evolutiva - 2 [DDE-2: battery for the assessment of developmental dyslexia and dysorthographia -2 ; hereafter, "DDE-2"] 35 were used to assess reading and writing accuracy. These tasks provided a total of four scores (two for accuracy and two for speed), generating a total of four scores. Children were considered to perform poorly if they failed at least one of the four items. In this study, we considered only the accuracy z-scores to identify all the children with reading disturbance.

\section{Assessment of malocclusion}

The children with DD were examined at the Orthodontic Department of the Second University of Naples in a quiet room without external noise, under artificial light. Each examination lasted approximately 15 minutes, following World Health Organization guidelines. ${ }^{36}$

Assessment of dental occlusion was carried out using latex gloves, dental mouth mirrors, and millimeter rulers. No radiographs, study casts, or previous written records were used. Personal data and information about orthodontic treatment were obtained directly from the children. The clinical examination was carried out by experienced orthodontists.

The orthodontic variables evaluated were as follows.

\section{Sagittal dimension}

Angle's classification was used to define the molar relationship: Angle's Class I, II, or III. The right and left antero-posterior molar relationships were scored in onequarter unit increments. A half unit Class II or half unit Class III was considered as Class II or Class III, respectively. "Overjet" (OJ) was defined as the distance from the most labial point of the incisal edge of the maxillary incisors to the most labial surface of the corresponding mandibular incisor and measured to the nearest $0.5 \mathrm{~mm}$, parallel to the occlusal plane. ${ }^{37}$

\section{Vertical dimension}

"Overbite" (OB) was considered the vertical overlap of the incisors when the posterior teeth were in contact. An edgeto-edge incisor relationship was recorded if the maxillary and mandibular incisors occluded on their incisal edges. ${ }^{37}$

\section{Transverse dimension}

A "posterior crossbite" was registered when the buccal cusps of the maxillary premolars and/or molars occluded lingual to the buccal cusps of the mandibular antagonists (at least one pair of teeth, uni- or bilateral).

Teeth in an edge-to-edge position were also included. A "scissorbite" was recorded when any of the maxillary premolars or molars occluded with the buccal surface of the mandibular antagonist teeth. The position of the maxillary midline was assessed relative to the mandibular midline (measured in lower incisor widths) to establish any discrepancy. ${ }^{37}$

\section{Alignment anomalies}

Diastemas were recorded for the anterior as well as for the posterior segments. A "midline diastema" was considered present when there was a space of at least $2 \mathrm{~mm}$ between the maxillary central incisors. ${ }^{37}$ 


\section{Statistical analysis}

To compare the characteristics (age, sex), the TIQ, reading abilities, and orthodontic features of the two samples, the Chisquare test and $t$-test were applied as appropriate. $P$-values $\leq 0.05$ were considered statistically significant.

All data were coded and analyzed using the commercially available STATISTICA package for Windows (version 6.0; StatSoft, Inc, Tulsa, OK, USA).

To evaluate the role of orthodontic abnormalities for DD development, univariate logistic regression analysis was performed for both studied samples using an online calculation program. ${ }^{38}$

\section{Results}

The DD sample comprised 28 children (22 males and six females; mean age: $9.78 \pm 1.69$ years) and the control group included 51 healthy children (38 males and 13 females; mean age $9.41 \pm 1.48)$. The two groups were not significantly different in terms of age $(P=0.320)$ or sex $(P=0.983)$.

The populations were comparable for TIQ $(P=0.441)$ and word $(P=0.805 ;)$ and non word $(P=0.240)$ writing skills whereas significantly higher z-scores were observed in dyslexic children for both word reading $(2.018 \pm 1.714$ vs $0.917 \pm 0.563 ; P<0.001)$ and non-word reading $(2.537 \pm 1.543$ vs $0.862 \pm 0.244 ; P<0.001)$ (Table 1$)$.

Regarding occlusal features, there was a higher prevalence of diastemas $(57.14 \%$ vs $23.52 \%, P=0.006)$ and midline diastemas $(46.42 \%$ vs $15.68 \%, P=0.007)$ in DD subjects. The prevalence rates of Class I ( $57.14 \%$ vs $70.58 \%$, $P=0.252)$, Class II (39.28\% vs $25.49 \%, P=0.361)$, and Class III ( $3.57 \%$ vs $3.92 \%, P=0.614)$ were not significantly different between the two study groups. DD subjects showed a higher prevalence of $\mathrm{OB}>4 \mathrm{~mm}(71.42 \%$ vs

Table I Comparison between children affected by developmental dyslexia (DD group) and typically developing children (control group) for total intelligence quotient (TIQ) and word and nonword reading and writing test

\begin{tabular}{lccl}
\hline & $\begin{array}{l}\text { DD, } \\
\text { mean } \pm \mathbf{~ S D ~} \\
(\mathbf{N}=\mathbf{2 8})\end{array}$ & $\begin{array}{l}\text { Control, } \\
\text { mean } \pm \mathbf{S D} \\
\mathbf{( N = 5 1 )}\end{array}$ & $\mathbf{P}$ \\
\hline TIQ & $101.37 \pm 8.32$ & $102.84 \pm 7.93$ & $0.44 \mathrm{I}$ \\
Word reading & $2.018 \pm 1.714$ & $0.917 \pm 0.563$ & $<0.00 \mathrm{I}$ \\
Non-word reading & $2.537 \pm 1.543$ & $0.862 \pm 0.244$ & $<0.00 \mathrm{I}$ \\
Word writing & $\mathrm{I} .114 \pm 0.832$ & $1.079 \pm 0.427$ & 0.805 \\
Non-word writing & $\mathrm{I} .189 \pm 0.276$ & $1.062 \pm 0.528$ & 0.240 \\
\hline
\end{tabular}

Notes: Student's $t$-test was performed; $P$-values $\leq 0.05$ were considered statistically significant.

Abbreviation: SD, standard deviation.
$58.83 \%, P=0.006)$ and $\mathrm{OJ}>4 \mathrm{~mm}(53.57 \%$ vs $29.41 \%$, $P=0.001$ ) than healthy children. Conversely, the healthy children showed a prevalence of OB $0-4 \mathrm{~mm}$ that was significantly higher than that of DD subjects $(41.17 \%$ vs $29.42 \%, P=0.0019$ ).

The two study groups did not differ significantly in terms of the rates of variables in the transverse plane $(17.85 \%$ vs $9.80 \%, P=0.499$ for crossbite; $14.28 \%$ vs $7.84 \%, P=0.499$ for unilateral crossbite; $3.57 \%$ vs $1.96 \%, P=0.754$ for bilateral crossbite; and $3.57 \%$ vs $3.92 \%, P=0.591$ for scissorbite). Moreover, in children affected by DD, a crossbite was present in $17.85 \%$, with a higher prevalence of unilateral crossbite $(14.28 \%)$ than bilateral crossbite $(3.57 \%)$ (Table 2).

According to the univariate logistic regression analysis, the presence of diastemas (odds ratio [OR] 4.33; 95\% confidence interval [CI] 1.61-11.65), midline diastemas (OR 4.68; 95\% CI 1.61-13.43), an OB > $4 \mathrm{~mm}$ (OR 1.75; 95\% CI 0.64-4.71), and an OJ > 4 mm (OR 2.76; 95\% CI 1.06-7.20) seems to play a role in the relationship between occlusal abnormalities and DD in children.

\section{Discussion}

"DD" can be considered a failure in age-appropriate learning of reading, despite adequate intelligence and appropriate opportunity; there is debate about the nature of the underlying deficit. As might be expected given the variety of theories of dyslexia that have been proposed, there are reports of performance deficits in a large number of tasks tapping different cognitive, sensory, and motor functions. ${ }^{39}$

Table 2 Findings of Chi-square test on prevalence of occlusal features between children affected by developmental dyslexia (DD group) and typical developing children (control group)

\begin{tabular}{|c|c|c|c|}
\hline & $\begin{array}{l}\text { DD, n (\%) } \\
(N=28)\end{array}$ & $\begin{array}{l}\text { Control, n (\%) } \\
(N=5 I)\end{array}$ & $\boldsymbol{P}$ \\
\hline Class I & $16(57.14)$ & $36(70.58)$ & 0.252 \\
\hline Class II & I I (39.28) & $13(25.49)$ & 0.361 \\
\hline Class III & I (3.57) & $2(3.92)$ & 0.614 \\
\hline Posterior crossbite & $5(17.85)$ & $5(9.80)$ & 0.499 \\
\hline Posterior unilateral crossbite & $4(14.28)$ & $4(7.84)$ & 0.499 \\
\hline Posterior bilateral crossbite & I (3.57) & I (I.96) & 0.754 \\
\hline Scissorbite & I (3.57) & $2(3.92)$ & 0.591 \\
\hline Diastemas & $16(57.14)$ & $12(23.52)$ & 0.006 \\
\hline Midline diastemas & I3 (46.42) & $8(15.68)$ & 0.007 \\
\hline Overbite $0-4 \mathrm{~mm}$ & $8(29.42)$ & $21(4 I .17)$ & 0.019 \\
\hline Overbite $>4 \mathrm{~mm}$ & $20(71.42)$ & $30(58.83)$ & 0.006 \\
\hline Overjet $0-4 \mathrm{~mm}$ & $13(46.43)$ & $36(70.59)$ & 0.061 \\
\hline Overjet $>4 \mathrm{~mm}$ & $15(53.57)$ & I5 (29.4I) & 0.001 \\
\hline
\end{tabular}

Note: $P$-values $\leq 0.05$ were considered statistically significant. 
Thus, DD can be considered a multi-symptomatic and heterogeneous disorder incorporating a wide variety of cognitive $^{40}$ and neurological signs. ${ }^{12}$ As such, our findings about the higher prevalence in DD children compared with typically developing children of occlusal problems suggest the presence also of somatic complaints in DD comorbidities.

Moreover, in 1997, Frith distinguished between explanations at the cognitive level and the biological level, and suggested a causal role to the idea that dyslexia follows other language difficulties; ${ }^{41}$ pinpointing the concept of the relationship between problems in automating the skills back and cerebellar deficits. ${ }^{42-44}$

Moreover, in DD subjects posture control seems to be significantly related to reading discrepancy respect of normal children. ${ }^{43}$ In this light, the higher number of abnormal orthodontic features, particularly $\mathrm{OJ}>4 \mathrm{~mm}(P=0.001)$ and OB $>4 \mathrm{~mm}(P=0.006)$, in our sample could be interpreted as a sort of epiphenomenon of abnormal posture control in these subjects.

In contrast, in accordance with the cerebellum's role in language ${ }^{17}$ and its relationship to dyslexia, ${ }^{43,45,46}$ it could be hypothesized that the role of abnormalities in tongue movement that are under cerebellum control ${ }^{18}$ in DD, such as in midline dental occlusion pathological features (midline diastemas, OB, and OJ), could explain our results about the presence of diastemas (OR 4.33; 95\% CI 1.61-11.65), midline diastemas (OR 4.68; 95\% CI 1.61-13.43), an OB > 4 mm (sOR 1.75 ; 95\% CI 0.64-4.71), and an OJ $>4 \mathrm{~mm}$ (OR 2.76; 95\% CI 1.06-7.2) as risk factors for DD development.

However, the cerebellum is involved in the integration of information from sensory receptors and is also one location where the internal representation of the body mechanics is computed.$^{47}$ The cerebellum is central to the coordination and smoothness of movement, ${ }^{48}$ including balance responses, probably through modulating the timing and amplitude of movement in the whole body.$^{18}$ These responses are normally learnt and stored through repetition and become automatic. In the cerebellar hypothesis of dyslexia, deficits in motor coordination and smoothness compromise speech articulation, leading to inappropriate phonological representations and poor reading and writing skills. ${ }^{49}$ Moreover, the cerebellar hypothesis seems to predict that postural control may be compromised in DD due to a failure in automating the postural responses to the balance perturbations, thereby increasing the requirement for attentional resources to monitor the postural control system. However, dyslexics have attention deficiencies, ${ }^{50-52}$ characterized by their difficulty in reading and performing component skills, ${ }^{53,54}$ which may leave insufficient attentional resources for the maintenance of postural control. ${ }^{43}$

Conversely, the cerebral cortex communicates with the cerebellum via polysynaptic circuits, and separate regions of the cerebellum are connected to distinct cerebral areas, forming a complex topography, whereas the tongue representation is bilateral and the foot and hand representation are lateralized, as shown by resting-state functional connectivity magnetic resonance imaging study. ${ }^{55}$

To date, little is known about the primary determining factors of malocclusions. In most cases, the morpho-functional characteristics of dental occlusion are inherited toward normality, since genetic characters are usually dominant. However, the elements that participate in the development and maintenance of these characteristics of normality are numerous and sensitive, mainly in their interrelations. As a result, any modification to the functional mechanism (breathing, swallowing, articulation, and chewing) may alter the form, and the form may alter the function, consequently determining morpho-functional deviations and deformities. ${ }^{56-59}$ It is worth remembering that although bone tissue is one of the hardest tissues in the human body, it is also one of the most plastic and one of the most responsive to the forces generated during function. ${ }^{60}$ Muscle forces also influence dental positioning according to their duration and intensity. The forces resulting from articulation and swallowing, which are intermittent and of greater intensity than resting forces, which are considered continuous and of lower intensity, do not have a great influence on the teeth. ${ }^{61}$

However, the tongue could be considered the most important organ in the articulation of speech due to its ability to make fast changes of movement and shape. Therefore, when any type of abnormality prevents normal articulation with the related structures (lips, teeth, alveolar bones, hard palate, and soft palate), this may result in a phonological disorder. $^{62,63}$

In fact, the tongue's influence on occlusion can be explained by Proffitt et al's equilibrium theory of the teeth. ${ }^{28}$ Despite the common belief among orthodontists that the tongue's activity during swallowing is an important cause of $\mathrm{OB}$, data on tongue and lip pressures as determinants of the vertical position of teeth are still scant and inconclusive.

Moreover, Hiiemae and Palmer ${ }^{64}$ have indicated that the vertically directed pressures during swallowing are less intense in patients with an anterior OB than in patients with a normal vertical relationship. Therefore, if the tongue pressures were greater in OB patients than in the normal occlusion patients, it would be easy to understand how the tongue 
could prevent eruption. Resting tongue and lip pressures might logically affect the vertical position of the teeth just as they affect positioning in other planes of space. There is no reason to attach special importance to tongue pressures during speaking, except in dyslexic patients with an unusual tongue position or an altered resting posture. In the present study, children with DD had less developed reading skills and altered dental features, particularly in the area of the incisors (diastemas and midline diastemas; $P=0.006$ and $P=0.007$, respectively). These results suggest that a persistent different tongue kinematic profile may thus affect both the developmental variability of tongue-lip relationship and the occlusion.

Even if the relationship between malocclusion and psychological health could be considered as presumptive and debated, ${ }^{29,30,65,66}$ this preliminary study may shed light on part of this unexplored area.

The present study aimed to identify differences in occlusal features in children affected by DD, suggesting the importance of investigation of academic abilities during the orthodontic evaluation, in order to devise orthopedic and postural rehabilitative treatment with a putative effect on learning performance.

\section{Limitations}

The following limitations of this study need to be taken into account: subjects were recruited from a specific region in southern Italy, no follow-up data are available, and the study population was a small pediatric sample.

\section{Acknowledgments}

The authors thank Antonio Parisi, MD, and Anna Lisa Buonomo of the Centro Studi Delacato at S Agnello (Italy), for the recruiting of children.

\section{Disclosure}

The authors declare no conflicts of interest in this work.

\section{References}

1. American Speech-Language-Hearing Association. Learning Disabilities: Issues on Definition [relevant paper]. Rockville, MD: American SpeechLanguage-Hearing Association; 1991. Available from: www.asha.org/ docs/pdf/RP1991-00209.pdf. Accessed August 16, 2013.

2. Tan ML, Ho JJ, Teh KH. Polyunsaturated fatty acids (PUFAs) for children with specific learning disorders. Cochrane Database Syst Rev. 2012;12:CD009398.

3. Barbiero C, Lonciari I, Montico M, et al; CENDi (National Committee on the Epidemiology of Dyslexia) working group; Epidemiology of Dyslexia of Friuli Venezia Giulia working group (FVGwg). The submerged dyslexia iceberg: how many school children are not diagnosed? Results from an Italian study. PLoS One. 2012;7(10):e48082.
4. Cortiella C. 2009: The State of Learning Disabilities. New York, NY: National Center for Learning Disabilities; 2009. Available from: http:// www.ncld.org/images/stories/OnCapitolHill/PolicyRelatedPublications/ stateofld/StateofLD2009-final.pdf. Accessed August 2, 2013.

5. Shaywitz SE. Dyslexia. N Engl J Med. 1998;338(5):307-312.

6. World Health Organization (WHO). The ICD-10 Classification of Mental and Behavioural Disorders: Diagnostic Criteria for Research. Geneva: WHO; 1993. Available from: http://www.who.int/classifications/icd/en/GRNBOOK.pdf. Accessed August 2, 2013.

7. American Psychiatric Association (APA). Diagnostic and Statistical Manual of Mental Disorders: Fourth Edition; Text Revision. Washington DC: APA; 2000.

8. Shaywitz SE, Escobar MD, Shaywitz BA, Fletcher JM, Makuch R. Evidence that dyslexia may represent the lower tail of a normal distribution of reading ability. N Engl J Med. 1992;326(3):145-150.

9. Capellini SA, Coppede AC, Valle TR. Fine motor function of schoolaged children with dyslexia, learning disability and learning difficulties. Pro Fono. 2010;22(3):201-208. English and Portuguese.

10. Overvelde A, Hulstijn W. Implicit motor sequence learning in children with learning disabilities: deficits limited to a subgroup with low perceptual organization. Dev Neuropsychol. 2012;37(7):579-589.

11. Levi G, Capozzi F, Fabrizi A, Sechi E. Language disorders and prognosis for reading disabilities in developmental age. Percept Mot Skills. 1982;54(3 Pt 2):1119-1122.

12. Brookes RL, Tinkler S, Nicolson RI, Fawcett AJ. Striking the right balance: motor difficulties in children and adults with dyslexia. Dyslexia. 2010;16(4):358-373.

13. Esposito M, Carotenuto M, Roccella M. Primary nocturnal enuresis and learning disability. Minerva Pediatr. 2011;63(2):99-104.

14. Chaix Y, Albaret JM, Brassard C, et al. Motor impairment in dyslexia: the influence of attention disorders. Eur J Paediatr Neurol. 2007;11: 368-374.

15. Carman SN, Chapparo CJ. Children who experience difficulties with learning: mother and child perceptions of social competence. Aust Occup Ther J. 2012;59(5):339-346.

16. Faust RA. Childhood voice disorders: ambulatory evaluation and operative diagnosis. Clin Pediatr (Phila). 2003;42(1):1-9.

17. Fiez JA, Petersen SE, Cheney MK, Raichle ME. Impaired non-motor learning and error detection associated with cerebellar damage. A single case study. Brain. 1992;115 Pt 1:155-178.

18. Smith AM. Babinski and movement synergism. Rev Neurol (Paris). 1993;149(12):764-770. French.

19. Hanly S, Vanderberg B. Tip-of-the-tongue and word retrieval deficits in dyslexia. J Learn Disabil. 2010;43(1):15-23.

20. Cheng HY, Murdoch BE, Goozée JV, Scott D. Physiologic development of tongue-jaw coordination from childhood to adulthood. J Speech Lang Hear Res. 2007;50(2):352-360.

21. Carotenuto M, Esposito M, Pascotto A. Facial patterns and primary nocturnal enuresis in children. Sleep Breath. 2011;15(2):221-227.

22. Esposito M, Antinolfi L, Gallai B, et al. Executive dysfunction in children affected by obstructive sleep apnea syndrome: an observational study. Neuropsychiatr Dis Treat. 2013;9:1087-1094.

23. Esposito M, Carotenuto M. Intellectual disabilities and power spectra analysis during sleep: a new perspective on borderline intellectual functioning. J Intellect Disabil Res. Epub March 21, 2013.

24. Esposito M, Carotenuto M. Borderline intellectual functioning and sleep: the role of cyclic alternating pattern. Neurosci Lett. 2010;485(2): 89-93.

25. Carotenuto M, Esposito M, Parisi L, et al. Depressive symptoms and childhood sleep apnea syndrome. Neuropsychiatr Dis Treat. 2012;8: 369-373.

26. Bernstein M. The relation of speech defects and malocclusion. Am J Orthod. 1954;40:149-150.

27. Blyth P. The relationship between speech, tongue behaviour, and occlusal abnormalities. Dent Pract Dent Rec. 1959;10:11-20.

28. Proffitt WR, Fields HW Jr, Sarver DM. Contemporary Orthodontics. 4th ed. St Louis, MO: Mosby Elsevier; 2007. 
29. Burden DJ. Oral health-related benefits of orthodontic treatment. Semin Orthod. 2007;13(2):76-80.

30. Borzabadi-Farahani A. A review of the evidence supporting the aesthetic orthodontic treatment need indices. Prog Orthod. 2012;13(3): 304-313.

31. Ramus F, Marshall CR, Rosen S, van der Lely HK. Phonological deficits in specific language impairment and developmental dyslexia: towards a multidimensional model. Brain. 2013;136(Pt 2):630-645.

32. World Medical Association (WMA). WMA Declaration of Helsinki: Ethical Principles for Medical Research Involving Human Subjects. Ferney-Voltaire: WMA; 2008. Available at: http://www.wma.net/ en/30publications/10policies/b3/17c.pdf. Accessed February 16, 2013.

33. Orsini A, Picone L. WISC III: Contributo alla taratura Italiana [WISC III: contribution to the Italian calibration]. Florence: Giunti OS Organizzazioni Speciali; 2006. Italian.

34. Wechsler D. Wechsler Intelligence Scale for Children. 3rd ed. San Antonio, TX: The Psychological Corporation; 1991.

35. Sartori G, Job R, Tressoldi PE. DDE-2: Batteria per la Valutazione della Dislessia e della Disortografia Evolutiva - 2 [DDE-2: battery for the assessment of developmental dyslexia and dysorthographia - 2]. Florence: Giunti OS; 2007. Italian.

36. World Health Organization. Oral Health Care Systems: An International Collaborative Study. Geneva: WHO; 1985.

37. Borzabadi-Farahani A, Borzabadi-Farahani A, Eslamipour F. Malocclusion and occlusal traits in an urban Iranian population. An epidemiological study of 11- to 14-year-old children. Eur J Orthod. 2009;31(5):477-484.

38. Bland JM, Altman DG. Statistics notes: the odds ratio. BMJ. 2000;320(7247):1468. Available from: http://www.hutchon.net/ ConfidOR.htm. Accessed August 2, 2013.

39. Roodenrys S, Dunn N. Unimpaired implicit learning in children with developmental dyslexia. Dyslexia. 2008;14(1):1-15.

40. Ellis AW. Reading, Writing and Dyslexia: A Cognitive Analysis. 2 nd ed. Hove: Lawrence Erlbaum; 1993.

41. Vellutino FR. Dyslexia: Theory and Research. Cambridge, MA: MIT Press; 1979.

42. Frith U. Brain, mind and behaviour in dyslexia. In Hulme C, Snowling M, editors. Dyslexia: Biology, Cognition and Intervention. London: Whurr; 1997:1-19.

43. Brookes RL, Stirling J. The cerebellar deficit hypothesis and dyslexic tendencies in a non-clinical sample. Dyslexia. 2005;11(3):174-185.

44. Nicolson RI, Fawcett AJ, Dean P. Time estimation deficits in developmental dyslexia: evidence of cerebellar involvement. Proc Biol Sci. 1995;259(1354):43-47.

45. Fawcett AJ, Nicolson RI, Dean P. Impaired performance of children with dyslexia on a range of cerebellar tasks. Ann Dyslexia. 1996;46(1):259-283.

46. Fawcett AJ, Nicolson RI. Performance of dyslexic children on cerebellar and cognitive tests. J Mot Behav. 1999;31(1):68-78.

47. Bastian AJ. Learning to predict the future: the cerebellum adapts feedforward movement control. Curr Opin Neurobiol. 2006;16(6):645-649.

48. Diedrichsen J, Criscimagna-Hemminger SE, Shadmehr R. Dissociating timing and coordination as functions of the cerebellum. J Neurosci. 2007;27(23):6291-6301.
49. Ramus F, Rosen S, Dakin SC, et al. Theories of developmental dyslexia: insights from a multiple case study of dyslexic adults. Brain. 2003;126(Pt 4):841-865.

50. Nicolson RI, Fawcett AJ. Automaticity: a new framework for dyslexia research? Cognition. 1990;35(2):159-182.

51. Nicolson RI, Fawcett AJ, Berry EL, Jenkins IH, Dean P, Brooks DJ. Association of abnormal cerebellar activation with motor learning difficulties in dyslexic adults. Lancet. 1999;353(9165):1662-1667.

52. Petkov CI, O’Connor KN, Benmoshe G, Baynes K, Sutter ML. Auditory perceptual grouping and attention in dyslexia. Brain Res Cogn Brain Res. 2005;24(2):343-354.

53. Rochelle KS, Talcott JB. Impaired balance in developmental dyslexia? A meta-analysis of the contending evidence. J Child Psychol Psychiatry. 2006;47(11):1159-1166.

54. Rochelle KS, Witton C, Talcott JB. Symptoms of hyperactivity and inattention can mediate deficits of postural stability in developmental dyslexia. Exp Brain Res. 2008;192(4):627-633.

55. Buckner RL, Krienen FM, Castellanos A, Diaz JC, Yeo BT. The organization of the human cerebellum estimated by intrinsic functional connectivity. J Neurophysiol. 2011;106(5):2322-2345.

56. Jabur LB. Inter-relação entre forma e função na cavidade oral [Interrelationship between form and function in the oral cavity]. In: Marchesan IQ, Bolffi C, Gomes IC, Zorzi JL. Tópicos em Fonoaudiologia [Topics in speech]. São Paulo: Lovise; 1994:223-225. Portuguese.

57. Jabur LB. Avaliação fonoaudiológica [Speech evaluation]. In: Vellini-Ferreira F, with Cotrim-Ferreira FA, Mercadante MM, Tormin AC, et al. Ortodontia Diagnóstico e Planejamento Clínico [Clinical orthodontic diagnosis and planning]. 5th ed. São Paulo: Artes Médicas; 2002:281-319. Portuguese.

58. Lino AP. Introdução ao problema da deglutição atípica [Introduction to the problem of atypical swallowing]. In: Interlandi S. Ortodontia: Bases para a Iniciação [Orthodontics: bases for initiation]. São Paulo: EDUSP; 1997:231-250. Portuguese.

59. Marchesan IQ. The speech pathology treatment with alterations of the stomatognathic system. Int J Orofacial Myology. 2000;26:5-12.

60. Graber TM. Orthodontics: Principles and Practice. Saunders; 1972.

61. Ingervall B, Sarnäs KV. Comparison of dentition in lispers and non-lispers. Odontol Revy. 1962;13:344-354.

62. Kent K, Schaaf NG. The effects of dental abnormalities on speech production. Quintessence Int Dent Dig. 1982;13(12):1353-1362.

63. Laine T, Jaroma M, Linnasalo AL. Relationships between interincisal occlusion and articulatory components of speech. Folia Phoniatr. 1987;39(2):78-86.

64. Hiiemae KM, Palmer JB. Tongue movements in feeding and speech. Crit Rev Oral Biol Med. 2003;14(6):413-429.

65. Ackerman MB. Selling orthodontic need: innocent business decision or guilty pleasure? J Med Ethics. 2010;36(5):275-278.

66. Borzabadi-Farahani A. A review of the oral health-related evidence that supports the orthodontic treatment need indices. Prog Orthod. 2012;13(3):314-325.
Neuropsychiatric Disease and Treatment

\section{Publish your work in this journal}

Neuropsychiatric Disease and Treatment is an international, peerreviewed journal of clinical therapeutics and pharmacology focusing on concise rapid reporting of clinical or pre-clinical studies on a range of neuropsychiatric and neurological disorders. This journal is indexed on PubMed Central, the 'PsycINFO' database and CAS.

\section{Dovepress}

The manuscript management system is completely online and includes a very quick and fair peer-review system, which is all easy to use. Visit http://www.dovepress.com/testimonials.php to read real quotes from published authors. 